\title{
Brasilidade Televisiva e Ritos Reality de Personalização
}

\author{
Suzana Kilpp ${ }^{1}$ \\ Universidade do Vale do Rio dos Sinos \\ sukilp@unisinos.br \\ Sonia Montaño² \\ Universidade do Vale do Rio dos Sinos \\ soniam@unisinos.br
}

\begin{abstract}
Resumo: Em Big Brother Brasil e Casa dos Artistas são feitas enunciações sobre o jogo (a vida), os jogadores (os atores sociais) e a realidade (a sociedade brasileira). Diferentes práticas enunciativas, relacionadas aos mundos televisivos da Rede Globo e do SBT, mostram os corpos eletrônicos preferidos das emissoras, que se aliam para excluir todos que não sejam o televisivo brasileiro vencedor. Esses reality shows vêm configurando novas personas televisivas que serão aqui analisadas.
\end{abstract}

Palavras-chave: Brasilidade televisiva; reality shows; personalizações reality.

Abstract: In Big Brother Brasil and Casa dos Artistas enunciations about the play (the life), the players (the social actors) and the reality (the Brazilian society) are made. Different practical enunciative, related to the television worlds of the Net Globo and the SBT, show the preferred electronic bodies of the broadcasting stations, that they are entered into an alliance to exclude all that are not the television "Brazilian winner". These reality shows come configuring new television persons that here will be analyzed.

\footnotetext{
${ }^{1}$ Suzana Kilpp é professora do Programa de Pós-Graduação em Comunicação na Universidade do Vale do Rio dos Sinos - UNISINOS. Doutora em Ciências da Comunicação, é líder do Diretório de pesquisa (CNPq) Metodologias de pesquisa e experimentação em audiovisual e coordena o Grupo de Pesquisa em Audiovisualidades.

${ }^{2}$ Sonia Montaño é jornalista e aluna do Programa de Pós-Graduação em Comunicação na Universidade do Vale do Rio dos Sinos - UNISINOS, em nível de mestrado.
} 
Keywords: Brazilian televising; reality shows; reality personalization

Résumé: Dans les programmes Big Brother Brasil et Casa dos Artistas il y a des enoncés sur le jeu (la vie), les joueurs (les acteurs sociales) et la réalité (la société brésilienne). La Rede Globo et le SBT montrent les corps électroniques préférés par les émissions de télévision. Elles excluent dans leurs différentes pratiques, tous ce qui ne correspond pas au "brésilien gagnant". Ces reality shows sont entrains de configurer des nouvelles personnes télévisives que seront analysés ici.

Mots-clé: Brésilien télévisives; reality shows; personnalisation reality

Resumen: En Big Brother Brasil y Casa dos Artistas se hacen enunciaciones sobre el juego (la vida), los jugadores (los actores sociales) y la realidad (la sociedad brasilera). Diferentes prácticas enunciativas, relacionadas a los mundos televisivos de la Red Globo y del SBT, muestran los cuerpos electrónicos preferidos de las emisoras, que se alían para excluir todo lo que no sea el televisivo "brasilero vencedor". Esos reality shows vienen configurando nuevas personas televisivas que serán analizados aquí.

Palavras clave: Brasilidad televisiva; reality shows; personalizaciones reality

\section{Brasis imaginados pela televisão, uma introdução}

Muitas vezes se disse que não existe um, mas dois brasis: um rico e outro pobre; um moderno e outro atrasado; um euro-americano e outro tupiniquim; um das elites e outro do povo; um da casa grande e outro da senzala, um que aparecia no Jornal Nacional e outro que era "real". Essas falas têm a ver com o chamado dilema brasileiro e tentam explicar quem nós somos em oposição a quem eles são. Lembram Augusto Comte, que pensava as sociedades em termos de seu progresso e atraso, e atestam a influência do Positivismo sobre os pensadores brasileiros.

Esses dois brasis são também construções técnicas e estéticas que se dão a ver em panoramas televisivos das duas emissoras de maior audiência no país, sendo que o brasil institucional, dos cidadãos e do presente moderno 
aparece mais na Rede Globo de Televisão, e o do compadrio, das pessoas ${ }^{3}$ e do passado atrasado, no SBT. No conjunto da programação das emissoras há inúmeras imagens que o atestam. Aqui, vamos nos deter apenas nas que estão implicadas nos dois reality shows de maior audiência no país: os programas Big Brother Brasil e Casa dos Artistas. São os que têm a casa como cenário e os que mais remetem à cotidianidade domiciliar como ethicidade4 enunciada pela TV, e que, por razões que veremos a seguir, também criam certos imaginários de país. Diferentes em cada uma das emissoras, esses imaginários permitem fazer algumas associações com determinados "brasis" e com determinados "brasileiros", porque são minimamente compartilhados com os de outros mundos.

Às identidades nacionais assim imaginadas pelas duas emissoras (como de resto todas as emissoras brasileiras) estamos chamando nesse artigo de brasilidade televisiva. A Rede Globo age muito mais que as outras na enunciação da nação brasileira, enquanto que o SBT age muito mais que as outras na enunciação do domicílio (dos brasileiros). Algumas razões disso serão tratadas no decorrer do texto.

\section{Personas televisivas e jogos reality de inclusão e exclusão em mundos televisivos}

A televisão tem suas próprias formas de promover a inclusão e a exclusão social. Sem serem espelho da sociedade, suas formas, entretanto têm a ver com as da sociedade. À “sociedade” engendrada técnica e esteticamente pela tevê em seus panoramas estamos designando de mundos televisivos, em relação aos quais consideramos a existência de um jogo de visibilidades, mais ou menos sólidas e fluidas, de seres televisivos (as ethicidades).

\footnotetext{
${ }^{3}$ Em todo o texto estaremos utilizando os conceitos de pessoa e indivíduo nos termos em que Roberto DaMatta os usa para analisar a sociedade brasileira.

${ }^{4}$ Ethicidades são seres (pessoas, objetos, fatos, durações, acontecimentos) que a TV dá a ver como tais, mas que são na verdade construções televisivas. (Ver Kilpp, 2003)
} 
Reality shows são jogos tipicamente assim. Neles, a TV tende a mostrar mais claramente sob que lógica funciona cada emissora no que concerne às visibilidades que deseja oferecer ao seu público. Reality shows são jogos performáticos de exclusão de todos menos um, nos quais, ao mesmo tempo, cada jogador tem um perfil ao qual podem ser associados inúmeros jogadores implícitos, reconhecíveis por certas estratégias de jogo ou de sobrevivência. Neles, para vencer, basicamente é preciso não se deixar excluir, o que pode significar desde estar o tempo todo agindo em função da estratégia dos outros até ficar o tempo todo na sua.

Reality shows também podem ser pensados como programas em que assistimos à experiência lúdica e catártica do limiar, do limbo entre o dentro e o fora, e não deve ser por acaso que o primeiro reality show realizado no Brasil, pela TV Globo, se chamasse justamente No limite. Ou seja, nada na TV brasileira mantém-se sem converter-se em entretenimento, nem mesmo o jogo por excelência da exclusão, o que não quer dizer que nos programas não haja importantes enunciações sobre essa exclusão desde a perspectiva mais duradoura (do que cada edição de cada programa) das emissoras.

Jost aborda, entre outros, dois tipos de jogos que interessam aqui: aqueles que são fundados numa decisão que não depende do jogador, relacionados à sorte e cujo prazer advém do próprio jogo, e aqueles que se centram na disputa, coletiva ou individual, física ou cerebral. Nesse caso, a "satisfação do candidato não vem mais da atividade lúdica enquanto tal, mas da sanção simbólica”. Sobre o competidor deste jogo recai um reconhecimento ou mérito (Jost, 2004: 39).

Assim, embora os dois reality shows que estamos analisando sejam freqüentemente tratados como sendo a mesma modalidade de jogo, gostaríamos de propor que não são. Gostaríamos de propor que, neles, as emissoras escancaram enunciações de jogo (a vida), de jogadores (os atores sociais) e de realidade (a sociedade brasileira) que praticam habitualmente, de 
formas mais ou menos veladas, noutros lugares. Na origem, estão os dois olhares referidos no início sobre o Brasil: uma sociedade enunciada em que se (sobre) vive dos favores de padrinhos, e outra em que existe livre concorrência e (sobre) vive o melhor.

A proposição que fazemos decorre da constatação de que na programação do SBT em geral predominam jogos de auditório e os jogos de sorte, nos quais prevalecem decisões que não dependem do jogador: ganhamse prêmios por total (ou quase total) providência de alguém, sendo que as regras podem ser facilmente mudadas durante o jogo. Há um visível apadrinhamento, que é enunciado positivamente, e que, reconhecendo que vivemos numa sociedade desigual, propõe estratégias de ascensão social baseadas em boas relações pessoais com as pessoas certas, dentre as quais destaca-se exemplarmente o perfil e a performance da persona televisiva Silvio Santos.

Na programação da Globo, ao contrário, os jogos que são enunciados como tais são menos expressivos (mas existem). Quando enunciados como jogos ou quando enunciados como outra coisa, destacam-se neles a livre concorrência, o esforço e o mérito pessoal dos indivíduos, a impessoalidade da emissora, o cumprimento igualitário e a inviolabilidade da regra.

Nos dois reality shows, em decorrência disso, sugerem-se perfis e performances diferentes daquelas que estamos chamando de novas personas televisivas, aquelas que devem mais facilmente ascender nos mundos imaginados pelas emissoras.

\subsection{Personas televisivas}

Mundos televisivos são constituídos em sua cotidianidade, em seu hábito não expressamente ficcional, principalmente de apresentadores de programas. Outros corpos eletrônicos são engendrados, porém, e outras máscaras são perfiladas regularmente nos panoramas televisivos, quase 
sempre em torno dos apresentadores. Esses outros corpos participam de um jogo de visibilidades, um jogo no qual há brechas para a aparição estranhada do habituado e para a aparição do estranho ao habituado.

É assim que uma certa quantidade e tipo de personas televisivas dão lugar, de tempos em tempos, ao que estamos chamando de novas personas televisivas. Defendemos que big brothers e artistas reality são as atuais novas personas. São novas porque, sem as benesses dos profissionais de carreira da TV, são, no entanto mais profissionais que "a adúltera”, "o travesti”, “o corno”, “a que busca saber quem é o pai de seu filho", "o que ainda não superou o complexo de Édipo", “aquele cujo irmão foi assassinado pela ex-mulher que está fugitiva", e tantos outros, personas de programas como o do Ratinho (SBT) ou o Linha Direta (Globo), por exemplo, novidades que lhes precederam. Esses semi-especialistas - como grande parte dos telespectadores, eles são semi-especialistas em reality shows - talvez justamente por isso estão ofuscando, no imaginário, o brilho do ator e do apresentador (os especialistas), que nunca seremos, já sabemos.

À semelhança do que ocorre em outros mundos imaginados, big brothers e artistas reality são personas construídas num coletivo que as irmana, distintivamente umas às outras, a partir de processos de sociabilidade e práticas identitárias. Ora, desde os nomes dos programas (Casa dos Artistas e Big Brother Brasil) há sentidos identitários sendo enunciados às personas reality, que nós devemos entender como nossos irmãos ou como os artistas que também podemos ser. Depois, selecionados como indivíduos que são parte de uma multidão solitária e anônima (ou quase) de brasileiros, esses irmãos e artistas passam o tempo todo, sob nossas vistas, por uma série de rituais 5 reality de personalização, em muitos aspectos semelhantes aos de pessoalização que temos na sociedade brasileira.

\footnotetext{
${ }^{5}$ Para DaMatta (1997:31) é por meio do rito que se podem atualizar estruturas de autoridade, permitindo situar, dramaticamente e lado a lado, quem sabe e quem não
} 


\section{Personalizações reality}

Inicialmente vejamos como se engendra as personas reality - o que ocorre a partir do que chamamos de rituais reality de personalização. Depois, a partir disso, discutiremos um pouco mais as personas televisivas e o papel dos reality shows em pauta na sua atual configuração. Focaremos três categorias interessantes: a dos apresentadores dos programas, a dos brothers e a dos artistas.

\subsection{A personalização dos apresentadores}

Apresentadores de TV são uma moldura 6 importante dos programas que apresentam, participando decisivamente dos sentidos identitários ali enunciados a um sem número de ethicidades. Eles podem ser mestres de cerimônia, maestros, âncoras ou entrevistadores, e sempre são porta-vozes das emissoras, aqueles que se dirigem a nós em nome da televisão, a sua vez autorizada a falar em nome dos brasileiros7. Idiossincráticos, eles habituam milhões de telespectadores a um rosto e voz, e a uma certa forma de adentrar nossas casas: são corpos eletrônicos daquelas personas; são corpos e máscaras quase sempre em primeiros planos (visus) de um personagem televisivo dele mesmo; são os corpos em torno dos quais visivelmente gravitam permanentemente os visíveis (ou não) corpos da equipe de produção, e os corpos mais efêmeros e transitórios de entrevistados, convidados, jogadores,

sabe, quem tem e quem não tem, quem está em contato com os poderes do alto e quem se situa longe deles. Não é, pois, por motivos estéticos (ou apenas estéticos, acrescentamos) que em todos os ritos sempre encontramos um centro, uma zona focal, geralmente controlada por um sacerdote ou quem faz a vez dele. No nosso caso, o apresentador de programa.

${ }^{6}$ Molduras são quadros de experiência e significação de seres televisivos, as ethicidades. As imagens audiovisuais de TV são sintetizadas em panoramas tipicamente televisivos, instaurados a partir de um compósito de molduras sobrepostas: canal, emissora, gênero, unidades autônomas (programas, promos, anúncios), programação (grade matriz, grade e programação em fluxo), panoramas televisivos e moldurações intrínsecas a eles. (Ver Kilpp, 2003)

${ }^{7}$ Lembramos aí que as emissoras de TV são cessionárias de canais públicos, e lembramos também as falas autorizadas a que se refere Marilena Chaú em $O$ discurso competente e outras falas. 
platéia, etc. Nos reality shows é o apresentador quem parece assegurar o equilíbrio da disputa e estabelecer nexo entre os mais variados recortes feitos na edição do programa. Sua posição é perspectivada, estratégica e central, e passam por ele as manifestações dos jogadores ao vivo e os diversos VTs editados na casa. No caso de Silvio Santos, ele é também aquele que faz a mediação com uma platéia de "colegas" sempre presente no monitor; Silvio nunca aparece fora do seu estúdio e sem seu auditório, que fica longe da casa cenário do programa. Pedro Bial, diferentemente, só interage com uma platéia em certas fases do jogo. Não é a sua platéia, mas a dos big brothers em pauta na ocasião ${ }^{8}$, e fica acomodada na rua cenário (que é extensão da casa cenário do programa), na área do grande estúdio Projac.

As idiossincrasias de cada apresentador ajudam a compreender os sentidos que as emissoras privilegiam nos brasileiros moldurados em cada programa, como veremos a seguir.

\subsubsection{Silvio Santos}

O apresentador de Casa dos Artistas, que é também apresentador de outros programas do SBT, emissora da qual é o dono, é em geral chamado pelo prenome artístico, Silvio.

Senor Abravanel, primeiro de seis filhos de um imigrante grego com uma cidadã turca de origem judaica, começou a ganhar dinheiro vendendo carteirinhas de plástico para guardar título de eleitor, no Rio, e sua carreira artística começou em 1952, quando fez teste na Rádio Guanabara. Sua estréia na televisão aconteceu em 1961 na antiga TV Paulista (que se tornou depois a TV Globo de São Paulo), tendo assumido o comando de $O$ Baú da Felicidade em 1968, programa que durava seis horas na TV Globo.

\footnotetext{
${ }^{8}$ Nos dias de paredão, por exemplo, cada big brother tem a sua platéia ou torcida ali presente: são familiares e amigos, principalmente. 
Não encontramos, na biografia do empresário, referências às razões da mudança de nome, mas o sugestivo comentário de seu biógrafo, comparando sua enorme popularidade à de um Deus, parece aproximá-lo de tantas santidades (patrões, protetores e padroeiros) com as quais, segundo DaMatta, nós, brasileiros, temos intimidade. Diz o autor que

\begin{abstract}
Em todos os casos, a relação existe e é pessoal, isto é, fundada na simpatia e na lealdade dos representantes deste mundo e do outro. Somos fiéis devotos de santos e também cavalos de santo de orixás, e com cada um deles nos entendemos muito bem pela linguagem direta da patronagem ou do patrocínio místico. (DaMatta, 2001:114-115)
\end{abstract}

Silvio Santos caracteriza-se por algumas marcas muito pessoais usadas em todos os programas por ele apresentados. Uma delas é o microfone segurado por um suporte em torno do pescoço. Evidentemente esse recurso não é da ordem da técnica, e diríamos que o SBT faz tanta questão de mostrar esse microfone (mais ligado à era do rádio ou aos inícios da TV e à cultura oral) quanto a Globo gosta de mostrar câmeras e monitores, mais ligados à era da imagem. Além disso, Silvio é em geral enquadrado, assim como âncoras de telejornais, em planos médios, e atrás de uma bancada que, nesse enquadramento (ou no do Ratinho, em situação similar) parece ser uma clara referência ao longínquo balcão do camelô que se tornou o bem sucedido megaempresário.

Uma outra característica do apresentador é justamente a ancoragem realizada pelos enquadramentos e a edição das seqüências, sempre alternando planos e contra-planos do artista apresentador: Silvio - colegas da platéia Silvio - convidados - Silvio - colegas artista(s) - Silvio -..., sendo ele geralmente enquadrado em um plano médio, postado atrás da bancada citada, com a logomarca do programa por trás. 
No reality sohw, que é um quadro do grande programa9 ${ }^{9}$ Silvio Santos, ele conversa com os artistas da Casa através da tela de um monitor situado na parede da sala. O único objetivo dessa tela parece ser permitir que tal diálogo tenha visibilidade, mas mesmo assim, são raros os enquadramentos que permitem ver Silvio Santos no monitor da Casa: na maior parte das vezes, na tela de nossa TV ele aparece no estúdio ao lado de sua platéia.

Essa centralidade quase absolutista aparece ainda nas decisões inusitadas que toma, acima de toda norma, como, por exemplo, prolongar a permanência de alguém na casa, ou mudar o número de votos necessário para alguém sair, ou, inclusive, decidir que, numa semana, ninguém sai.

Além disso, o apresentador mostra claramente preferência por um ou outro participante dos programas, e questiona decisões que os participantes ou os telespectadores que dão seu voto pelo telefone estão tomando. Mais do que negar a objetividade imparcial do mediador, tais atitudes são todas, ao final e no conjunto, idiossincrasias folclóricas do pai-patrão e do bom "compadre".

\subsubsection{Pedro Bial}

Autor da mais recente biografia de Roberto Marinho, patriarca da família à qual pertencem as Organizações Globo, o apresentador de Big Brother é em geral chamado pelo sobrenome (Bial) ou então de jornalista (Pedro Bial). ${ }^{10}$

\footnotetext{
${ }^{9}$ Na grade de programação da emissora é difícil distinguir os diversos programas apresentados semanalmente por Silvio Santos. Tendemos a perceber um grande programa com muitos quadros, espalhados em vários horários nos domingos e em certas noites da semana.

${ }^{10}$ Embora seja mais conhecido como jornalista, Bial também tem vinculação com o cinema (dirigiu os filmes Outras Estórias e Os Nomes do Rosa, ambos baseados no livro Primeiras Histórias, de Guimarães Rosa) e com a poesia (foi membro de $O s$ Camaleões, grupo de recitais que se formou na década de 80, e atualmente participa do Ver o Verso).
} 
Bial é carioca, descendente de alemães. Formado pela PUCRJ em 1980, já em 1981 começou a trabalhar na Rede Globo. Entrou para a equipe do Globo Repórter em 1984, em 1988 tornou-se correspondente em Londres, e mais tarde transmitiu importantes acontecimentos, como a queda do muro de Berlim e a guerra do Golfo. A partir de sua experiência como correspondente Bial escreveu Crônicas de Repórter e Leste Europeu: A Revolução ao Vivo, este em parceria com Renée Castelo Branco.

Até entrar no programa, o apresentador era conhecido principalmente como correspondente internacional, que é uma função muito respeitada entre jornalistas e tida como séria ${ }^{11}$ entre nós, brasileiros. Mas, de volta ao Brasil, em 1996 passou a apresentar o Fantástico $^{12}$, talvez a guinada que o acabaria levando finalmente ao Big Brother.

Entendemos que Bial é o apresentador certo, provavelmente escolhido a dedo, para o caráter que a emissora deseja que o programa tenha: de jornalismo, de jornalismo sério e popular, de jornalismo ainda mais popular que o do Fantástico. A credibilidade de Bial junto aos pares sérios, entretanto, foi abalada, já na época do Fantástico, um programa considerado menos sério porque faz um jornalismo mais "popular"; e só piorou quando assumiu o Big Brother. Em resposta, numa entrevista à revista Trip, o apresentador propôs que

Fazer televisão popular é um puta desafio. Fui um adolescente meio esnobe. Me achava superior aos colegas porque lia Carlos Drummond de Andrade. E carreguei essa dificuldade de fazer TV popular. Então, estou adorando conseguir isso. O século XX acabou com as barreiras entre a alta e a baixa cultura, mas ainda é uma grande zona... Acho legal se eu puder fazer uma ponte. (Revista Trip, junho 2003, 110 a ed., p. 22-30)

Seja porque ponte (na percepção de Bial), seja por causa da seriedade que cercava sua imagem de jornalista (ao menos até o Fantástico), o ex-

\footnotetext{
${ }^{11}$ Nos termos em que Roberto Gomes (1986) distinguiu, por exemplo, o sério intelectual brasileiro de terno e gravata do humorismo brasileiro feito a sério. ${ }^{12}$ E o Espaço Aberto, na Globo News.
} 
correspondente vem emprestando ao programa popularidade, seriedade e objetividade jornalísticas. Mas as moldurações praticadas pelo programa reforçam sobremaneira tais sentidos (todos), como veremos.

Em $B B B$, na telinha, o corpo eletrônico de Bial aparece só, em um estúdio fechado e asséptico (como uma bolha que o protege de contaminações e impurezas). Por trás dele há alguns monitores onde se alternam os elementos que formam a logomarca do programa, e uma tela maior na qual são mostradas, às vezes, imagens do interior da casa cenário. À sua vez, a imagem de Bial entra na sala da casa cenário onde estão os jogadores através de um monitor (cuja marca, Philco, fica bem visível na parte inferior do aparelho) inserido também na parede da sala.

À diferença de Silvio, Bial aparece dentro da casa sempre em um plano maior, pelo qual fica visível que sua presença na sala da casa é através de uma TV. Bial dirige-se muito mais ao telespectador, ao público domiciliado, e sua fala é mais impessoal. "Salve, salve", diz ele a cada abertura de programa; então, introduz um videoteipe (edição) do dia anterior ou da semana. Após esses VTs serem passados, Bial comenta o assunto do videoteipe e pode muitas vezes usá-lo na conversa com os jogadores. Em outras ocasiões ele mesmo faz um resumo dos acontecimentos da semana, que usa então na conversa com os participantes.

Depois de cada bloco do programa acontece mais ou menos a mesma coisa, sendo que no final ele se despede e incita o público a espiar ou a dar uma olhadinha no que está acontecendo ao vivo na casa cenário. Bial é também quem incita o público a votar e a detonar alguém, e quem explica ao público e aos participantes as provas semanais do líder.

$\mathrm{Na}$ hora do voto, ambos apresentadores falam com os participantes. Entretanto, seguindo a lógica já exposta, enquanto Silvio entabula uma relativamente longa e debochada conversação pessoal, Bial adota as falas muito mais breves, impessoais e objetivas do jornalista. 


\subsection{A personalização dos brothers}

O $B B B$ tende a ocultar em seus panoramas os vestígios de qualquer ênfase personalista no tratamento dos brothers, seguindo a mesma lógica asséptica que definiu o perfil do apresentador do programa. Já antes de uma edição ir ao ar, durante a programação da emissora ganha destaque uma forma muito aberta e imparcial - como um imaculado concurso público - de chamamento à inscrição, ao qual qualquer brasileiro pode responder, e concorrer em igualdade de condições às vagas existentes (doze, na edição analisada): basta o candidato enviar à emissora um vídeo e uma ficha de inscrição preenchida. Ora, há dois implícitos aí: não ser analfabeto nem pobre. Antes de tudo, para que seus corpos caibam nos panoramas clean da emissora, eles têm que ter esse padrão Globo de qualidade.

Se, de um lado ser selecionado e entrar na casa, e permanecer nela, implica ir se tornando persona, de outro lado não ser selecionado e não entrar seria, em tese, uma condenação ao anonimato dos indivíduos na multidão solitária. Mas não é isso que ocorre, pois a Globo vem reciclando e exibindo na Internet muitos dos vídeos enviados pelos não selecionados, personalizando esses indivíduos como sendo os mais risíveis e grotescos. Ou seja, na tentativa de justificar a seleção que fez, a emissora ritualiza a personalização (que nega) em duas direções opostas e complementares: as personas que cabem na casa e as personas que não cabem na casa.

Vejamos rapidamente alguns rituais $B B B$ a partir da seleção dos jogadores, que passam então a chamar-se brothers ${ }^{13}$. O apelido irmãos já indica uma leitura pelo ângulo da casa, ressaltando a pessoa. Como diz

\footnotetext{
${ }^{13}$ No Brasil, o Big Brother foi convertido silenciosamente em vários big brothers e o nome do programa é pouco relacionado ao personagem de George Orwel. Prevalecem os modos de significação pelo ângulo da irmandade-seleção brasileira, especialmente a do futebol. Aliás, DaMatta (1994) sugere o futebol como aquele ritual que promove uma horizontalização dos relacionamentos em nossa sociedade bastante hierarquizada. Uma vez que a igualdade de condições é necessária para (a graça d) o jogo, a paridade na disputa permitiria também a experiência (exemplar) das leis universais que nos governam e que, na vida cotidiana, são aplicadas desigualmente.
} 
DaMatta (1991:22), "nesses contextos [similares ao do programa], todos podem ter sido adversários ou até mesmo inimigos, mas o discurso indica que também são 'irmãos' porque pertencem a uma mesma pátria ou instituição social”.

O primeiro programa de cada edição apresenta os jogadores chegando individualmente, numa limusine, até a porta da casa, onde são entrevistados brevemente por uma repórter que acentua certas características pessoais (que serão ou não mantidas no engendramento das personas reality) e a estratégia que pretendem adotar para vencer. "Ser mãe”, “não ter estratégias”, "ser simples e espontâneo", "usar sua experiência profissional” (lutador, massagista, mergulhador), são alternativas de resposta.

A apresentação é rápida e é a própria repórter que abre a porta da casa aos participantes, em três momentos diferentes para que entrem em pequenos grupos. Mais do que uma questão de ordem prática parece um ritual, que se repete para que possamos perceber a entrada dos nossos irmãos, selecionados para nos representarem. A entrada na casa, nas palavras de Jost (2004:10), “é um texto (que) contém, com efeito, uma imagem de quem fala e mostra; do mesmo modo, comporta uma imagem de quem ouve e olha e, por isso, desenha uma relação entre os dois”. Para o autor, não existe uma relação real entre emissor e receptor, há uma relação construída entre dois seres virtuais esboçados no interior do texto. Daí essa sensação de um Brasil inteiro que entra na casa.

$\mathrm{Na}$ medida em que as eliminações acontecem, as edições do programa vão construindo os perfis que vão sendo replicados até se converterem em Dhominis e Elanes, figuras tão familiares que "não estão sozinhos, [pois] o Brasil tem milhões de Dhominis e Elanes”, como dirá o apresentador na abertura do programa final. 


\subsection{A personalização dos artistas}

A seleção, em $C A$, é, como tudo no SBT, mais personalista. Os participantes são sabidamente escolhidos pela produção do programa a partir de perceptíveis critérios pessoais, revelados expressamente na comparação com outros apresentadores e artistas do SBT, os supostos outros candidatos que são, no entanto, obviamente os descartáveis. ${ }^{14}$ Ou seja, os jogadores já entram na casa (e no SBT, em geral) como pessoas - aquelas pessoas.

Sua pessoalidade é reforçada no programa - no sentido destas pessoas e destes artistas - principalmente nas confidências e fofocas trocadas com Silvio, durante todas as semanas em que o programa está no ar e perceptível na telinha em enquadramentos fechados de câmara, que são mais dramáticos e subjetivos.

Os jogadores artistas são colegas de trabalho (sic) do apresentador, e o vínculo que entre si estabelecem remete não ao irmão de sangue, mas de ofício ${ }^{15}$; não ao pai, mas ao patrão. Sendo todos irmãos de ofício, então, vivendo na casa que é dos artistas (o SBT), Silvio se torna aquele irmão mais velho e já consagrado que tutela e decide (e por isso é o padrinho que ajuda a criá-los) o destino dos mais jovens e menos consagrados. Estes, à sua vez, disputam entre si por pequenos afagos; proteção e prolongamento da permanência ao seu lado; fama; dinheiro (“quem quer dinheiro?” É o que perguntava há algum tempo Silvio ao auditório, enquanto atirava as notas, em geral às mulheres que gritavam por ele).

E por uma casa! Ora, a casa - que já está no nome do programa - é uma ethicidade central nos mundos televisivos instaurados pelo SBT. Isso porque a casa está no centro de vários negócios da empresa: como imóvel

\footnotetext{
${ }^{14}$ Por exemplo, ao encenar um processo público de seleção, em seu programa de auditório, Silvio Santos dá a ver deliberadamente o personalismo que norteia suas escolhas.

${ }^{15}$ Tornar-se artista, segundo DaMatta, é um importante modo brasileiro de ao mesmo tempo tornar-se pessoa.
} 
adquirido por consórcio (Plano Minha casa, nosso lar, do Banco PanAmericano ${ }^{16}$ ); como prêmio de sorteios (do carnê do Baú da Felicidade e da Tele Sena); como brinde de jogos (o do Milhão, por exemplo); como um bem doado (no quadro de programa Porta da Felicidade, por exemplo).

Estamos propondo assim, que Silvio, casa e artistas são as mais importantes faces de uma mesma e única persona televisiva, a persona do SBT. Portanto, estar no SBT, estar no programa de Silvio Santos e participar da Casa dos artistas são reiterações e reverberações de um mesmo grande ritual de personalização.

\section{Considerações finais}

Roberto DaMatta diz que no Brasil, a pessoa tem relações que a revestem de uma peculiar humanidade, resgatando-a de sua condição anônima, genérica e universal de cidadão e de indivíduo. Já o indivíduo é um ser isolado, um "Zé ninguém. $\mathrm{O}$ indivíduo isolado e sem relações, a entidade política indivisa, é considerado como altamente negativo, revelando apenas a solidão de alguém que, sem ter vínculos, é um ser humano marginal em relação aos outros membros da comunidade" (DaMatta, 1991:89).

O que transforma o indivíduo em pessoa são as suas relações pessoais ou com as pessoas. As pessoas estão associadas às suas casas, ou à casa em geral, pois neste domínio cada um é uma realidade única, insubstituível e socialmente irreprodutível. "Na casa, longe de ser indiviso, estou francamente dividido por inúmeras lealdades pessoais que se demarcam pelo parentesco e pelos laços de simpatia pessoal". (DaMatta, 1991:99) ${ }^{17}$

\footnotetext{
${ }^{16}$ O Banco é um dos negócios do Grupo Silvio Santos.

${ }^{17} \mathrm{O}$ parentesco (identidade) pode ser biológico (como parece ser entre irmãos) ou ocupacional (como parece ser entre artistas). Nos dois programas, a casa enunciada é lugar identitário, como a casa de DaMatta. Mas a casa Brasil e a casa televisiva das duas emissoras são completamente outras. Essa análise está mais desenvolvida noutro artigo, de Kilpp e Almeida, intitulado Reality houses.
} 
Nos dois reality shows de que estivemos falando há ritos visíveis de personalização e, até o final de cada edição, teremos assistido, talvez inadvertidamente, a inúmeras performances - à brasileira, mas também ao jeitinho reality da Globo e do SBT -, que tiveram a finalidade, talvez insuspeitada pelos jogadores, de instaurar a autoridade personal de quem está falando. Pois é essa expressão (você sabe com quem está falando?) o que permite estabelecer a pessoa onde antes só havia o indivíduo.

Trata-se de parte importante de um ritual cotidiano, no qual qualquer brasileiro se reconhece facilmente, mas que revela um traço do qual não gostamos e que preferimos esconder, pois, afinal, o que vem à tona aqui não é a nossa celebrada e carnavalizada cordialidade, mas, ao contrário, o verdadeiro e profundo "esqueleto hierarquizante de nossa sociedade" (DaMatta, 1997: 220). O ritual, por mais que o pratiquemos, é desagradável. Não por si só, mas porque implica verbalizar o que não deveria ser preciso dizer: implica quebrar o pacto silencioso e cordial de uma sociedade em que se pressupõe que cada um sabe qual é o seu lugar ${ }^{18}$ sem precisar ser lembrado disso.

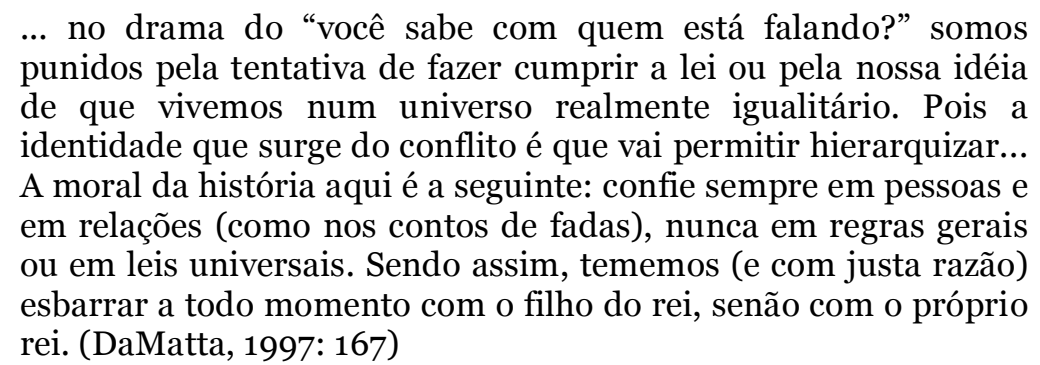

O ritual do você sabe... tem sua expressão própria na linguagem audiovisual e em cada uma das emissoras em questão. Como um todo, os programas já são uma primeira resposta à pergunta implícita: você está falando com um big brother ou com um artista! Ao final, a resposta mais definitiva é: você está falando com o brasileiro vencedor! (de $B B B$ ou de $C A$ ).

\footnotetext{
${ }^{18}$ Por exemplo, diz-se muito que no Brasil não existe preconceito de cor, ao que se acrescenta (ao menos mentalmente): porque aqui o negro sabe seu lugar...
} 
Esses que ali estão, como qualquer um de nós, semi-especialistas, personagens de si mesmos, novas personas televisivas, o moderno cidadão da moderna sociedade brasileira ou o tradicional e enquistado apadrinhado. Resguardadas as diferenças das personas da Globo e do SBT, nas quais insistimos, os inúmeros rituais de personalização praticados nos dois programas dão a ver esse duplo movimento: enquanto se enuncia o alargamento do espectro das visibilidades possíveis em mundos televisivos, reafirma-se de fato o tempo inteiro uma profunda e vergonhosa desigualdade e a necessidade, frente a isso, da interpelação - você sabe com quem está falando?.

É talvez porque a TV brasileira percebe (inclusive pelo Ibope) que não queremos mais permanecer no lugar que nos coube nessa estrutura hierarquizante - e porque também não confiamos em regras gerais ou em leis universais -, que se fez o pacto de audiência dessas novas personas televisivas e se proclama sem criticar a brasilidade televisiva como sendo a nossa. Não se trata de mudar os jogos reality, mas de conseguir deles participar. Parece que a TV vem nos fazendo acreditar nisso, e não podemos não lembrar aqui de Benjamin:

\section{A exploração capitalista do cinema impede a concretização da aspiração legítima do homem moderno de ver-se reproduzido (p.184). As massas têm o direito de exigir a mudança das relações de propriedade; o fascismo permite que elas se exprimam, conservando, ao mesmo tempo, essas relações (p.195). (Benjamin: 1986)}

Guardadas as diferenças, reconhecemos muitas semelhanças entre os filmes de movimento de que o autor fala com o que assistimos hoje com o fenômeno dos reality shows. 


\section{Referências:}

BENJAMIN, Walter. Magia e técnica, arte e política. São Paulo: Brasiliense, 1987.

CHAUÍ, Marilena. Cultura e democracia: o discurso competente e outras falas. São Paulo: Moderna, 1981.

DAMATTA, Roberto. A casa \& a rua. Espaço, cidadania, mulher e morte no Brasil. Rio de Janeiro: Guanabara Koogan, 1991.

.Carnavais, malandros e heróis. Para uma Sociologia do dilema brasileiro. 6.ed. Rio de Janeiro: Rocco, 1997.

. O que faz o brasil, Brasil? Rio de Janeiro: Rocco, 2001.

GOMES, Roberto. Crítica da razão tupiniquim. 9 ed. Curitiba: Criar, 1986.

HALL, Stuart. A identidade cultural na pós-modernidade. Rio de Janeiro: DP\&A, 2001.

JOST, François. Seis lições sobre televisão. Porto Alegre: Sulina, 2004.

KILPP, Suzana. Ethicidades televisivas. São Leopoldo: Editora Unisinos, 2003.

SILVA, Arlindo. A fantástica história de Silvio Santos. São Paulo: Editora do Brasil, 2000. 